\title{
Intermittent hypothermia Independence of central and reflex thermoregulatory mechanisms
}

\author{
RALPH H. JOHNSON AND DAVID M. PARK \\ From the University Department of Neurology, Institute of Neurological Sciences, \\ Southern General Hospital, Glasgow
}

SUMMARY Three patients who had suffered episodes of spontaneous hypothermia are described. Circulatory control was normal for their age but there was evidence of a persistent defect of thermoregulatory mechanisms. In all patients vascular thermoregulatory reflexes dependent upon peripheral receptors were active and in two patients reflex shivering could be obtained. There appeared, however, to be a failure of central thermoregulation as the vascular reflexes were active at abnormally low central temperatures and a fall in central temperature did not initiate shivering. It is concluded that in patients who have suffered spontaneous hypothermia there may be a persistent defect of central mechanisms subserving vasomotion and shivering, although thermoregulatory reflexes dependent upon peripheral receptors can be active. The reflex pathways for thermoregulation in man therefore have a separate integrity, physiologically independent of the central thermoregulatory mechanisms.

Episodes of hypothermia may occur in elderly subjects and their frequency and seriousness were stressed by a report from the Royal College of Physicians (1966). Elderly survivors of such episodes of accidental hypothermia may have a persistent impairment of body temperature regulation without evidence of other neurological abnormalities (Macmillan, Corbett, Johnson, Spalding, Smith, and Wollner, 1967). Hypothermia may result from lesions in the central nervous system which may be of a gross disruptive nature, as after head injury, cardiac arrest, or transection of the spinal cord. Alternatively hypothermia may occur as a result of discrete lesions affecting thermoregulatory centres in the hypothalamus (Bauer, 1954; Fox, Davies, Marsh, and Urich, 1970).

The nature of the central abnormality in elderly patients with episodic spontaneous hypothermia is still poorly understood. We therefore describe three further patients in whom we have found evidence that reflexes dependent on peripheral thermoreceptors can remain active when central receptor function has apparently failed.

\section{PATIENTS}

The patients were three women aged 63,69 , and 71 years. They had been admitted as emergencies with hypothermia. None had evidence of a primary neurological disorder.

Case 1 (E.N.), aged 69 years, had been admitted on three occasions over two years with hypothermia, oral temperatures ranging from $29 \cdot 4-31^{\circ} \mathrm{C}$. Her latest admission with a temperature of $29.5^{\circ} \mathrm{C}$ was on a warm summer day. At each admission she was confused, with rigidity of all four limbs, although the reflexes were normal. She had a past history of intermittent atrial fibrillation and congestive cardiac failure. There was no clinical or laboratory evidence of a focal neurological lesion or of an endocrine disorder. In between admissions she lived at home with a relative.

Case 2 (S.B.), aged 71 years, was first admitted six months before she died. She had been well until three weeks before admission when she started to become progressively more drowsy and confused. Three days before admission she ceased to speak and became confused. There was no other clinical abnormality and her oral temperature at that time was said to be $36 \cdot 1^{\circ} \mathrm{C}$. Subsequently her oral temperature with a low reading thermometer was $32^{\circ} \mathrm{C}$ and she was still confused. In spite of her low body temperature she did not shiver. She felt objectively warm to the touch and had no subjective sensation of cold. In the six months before her death she was able to walk about and cooperate but nevertheless her oral temperature was between $34^{\circ} \mathrm{C}$ and $35^{\circ} \mathrm{C}$. At 
necropsy there was no macroscopic evidence of central nervous system disease, although moderate cerebrovascular atheroma was present (Dr. M. Dunhill).

Case 3 (O.Y.), aged 63 years, was admitted for investigation of memory loss and delusions of persecution and, on admission, was found to have an oral temperature of $35 \cdot 3^{\circ} \mathrm{C}$. No other abnormalities were found on clinical examination. Soon after arrival in hospital her oral temperature was recorded as $33.5^{\circ} \mathrm{C}$ with a low reading thermometer. During the whole of her admission her temperature remained below $36^{\circ} \mathrm{C}$. There was no shivering. Objectively she felt warm to the touch and had no subjective sensation of cold. She was able to walk and cooperate. She was able to return home but died after having been found unconscious at home a year later. Pneumoencephalography during her first admission showed mild ventricular enlargement, and subsequent pneumoventriculography during her last admission showed gross hydrocephalus with partial obstruction of the aqueduct. At necropsy, the aqueduct was small but patent. There was dense gliosis of the tectum although the aetiology of this could not be defined (Dr. D. R. Oppenheimer).

\section{INVESTIGATIONS OF AUTONOMIC FUNCTION}

CARDIOVASCULAR REFLEXES The systemic arterial pressure was measured from a catheter in the brachial artery using a capacitance manometer and recording system. The manometer was fixed at the mid-sternal level and its calibration was checked at intervals throughout each investigation against a mercury manometer. Changes in heart rate were monitored with an electrocardiograph. The following tests were performed:

Change of posture Each subject was moved from supine to upright on a tilting table.

Valsalva's manoeuvre Each subject attempted a forced expiration for at least seven seconds through a face mask connected by a thick-walled rubber tube to a mercury manometer (Sharpey-Schafer, 1955). They attempted to maintain a constant pressure of 30-40 $\mathrm{mmHg}$.

Sudden noise and mental arithmetic A starting pistol was fired without warning. The blood pressure was also observed while a simple sequence of addition and subtraction was attempted.

THERMOREGULATORY FUNCTION The responses to both warming and cooling of the subjects were observed:
Radiant heating of trunk Central temperature was measured using an electrical thermometer (Ellab Instruments) with thermocouple applicators for the external auditory meatus and rectum. Skin temperature was measured (two investigations) at two sites on the trunk. Changes in hand blood flow were measured directly by venous occlusion plethysmography (case 3, O.Y.) or assessed by observing digital heat elimination (cases 1 and 2) using heat flow discs (Hatfield, 1950). These were $12 \mathrm{~mm}$ in diameter and were applied to the pulp of the index finger or $\vec{F}$ thumb of each hand and to the pulps of the big toes with the hand or foot immersed in a water bath at $28-30^{\circ} \mathrm{C}$. An increase in the galvanometer reading expressed as arbitrary galvanometer units indicated $a$ rise in digit heat elimination and vice versa (Cooper, $\triangle$ Johnson, and Spalding, 1964).

Body cooling Each subject was cooled gently with $\stackrel{\vec{\circ}}{-}$ electric fans while temperature was measured as $\vec{\omega}$ previously. Oxygen consumption was estimated using a Benedict-Roth spirometer. An additional cold stimulus was applied by placing the feet in cold $i$ water $\left(4^{\circ} \mathrm{C}\right)$ briefly for two periods during the $\frac{\sigma}{\omega}$ investigations.

\section{RESULTS}

The results of tests of circulatory reflexes a summarized in Table 1. They may all be cop sidered normal. The failure of a vasoconstrictor $\vec{\varphi}$

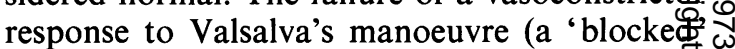
response) in case 1 (E.N.) was within the expected limits for patients with heart disease (Sharpey-Schafer, 1955) and for patients of this age (Gross, 1970).

Radiant heating of the trunk resulted in a rise $\frac{0}{\infty}$ of central temperature in all patients. In case $1 \overrightarrow{\vec{B}}$

TABLE 1

RESULTS OF TESTS OF CIRCULATORY REFLEXES IN THREE PATIENTS

\begin{tabular}{|c|c|c|c|}
\hline & $\begin{array}{c}1 \\
E . N .\end{array}$ & $\begin{array}{c}2 \\
\text { S.B. }\end{array}$ & $\stackrel{3}{O . Y .}$ \\
\hline $\begin{array}{l}\text { Age (yr) } \\
\text { Sex } \\
\text { Upright posture } \\
\text { Valsalva's manoeuvre } \\
\text { Noise } \\
\text { Heart rate response to: } \\
\quad \text { upright posture }\end{array}$ & $\begin{array}{c}69 \\
\text { F } \\
\text { No o } \\
\text { Blocked } \\
+\end{array}$ & $\begin{array}{c}71 \\
F \\
\text { ostatic hy } \\
\text { Normal } \\
+ \\
\end{array}$ & $\begin{array}{c}63 \\
\text { F } \\
\text { nsion } \\
\text { Normal } \\
+ \\
\end{array}$ \\
\hline + Present. & & & \\
\hline
\end{tabular}




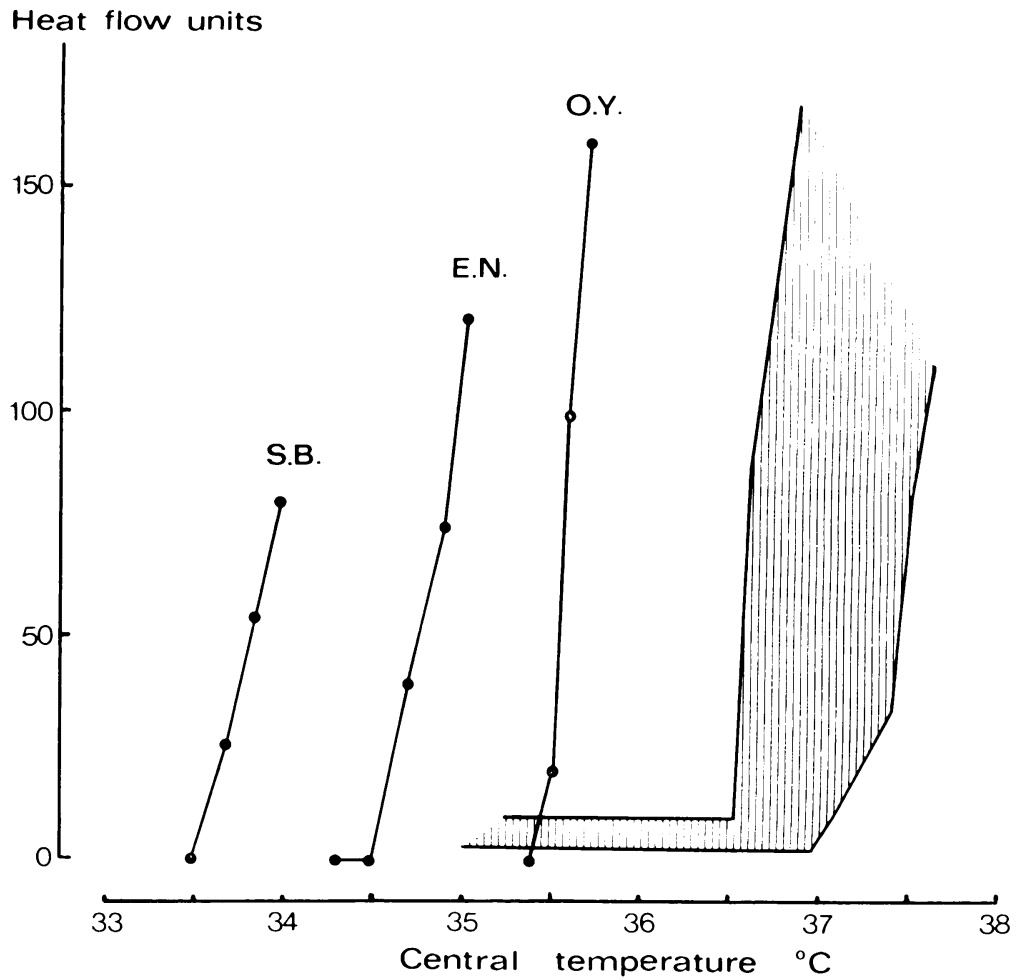

FIG. 1. Heat elimination from an index finger (galvanometer units) during radiant heating of the trunk in the three patients. The horizontal axis indicates the central temperature (external auditory meatus) at which the change in heat elimination occurred. The hatched area indicates the normal range described by Cooper, Johnson, and Spalding (1964).

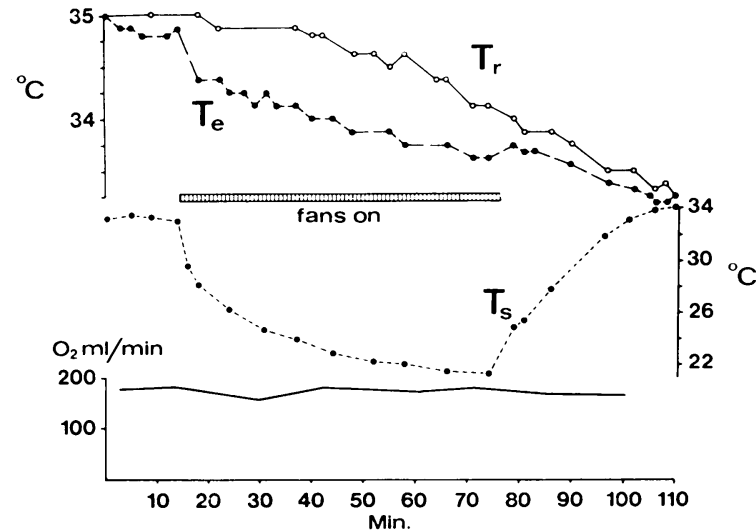

(a)

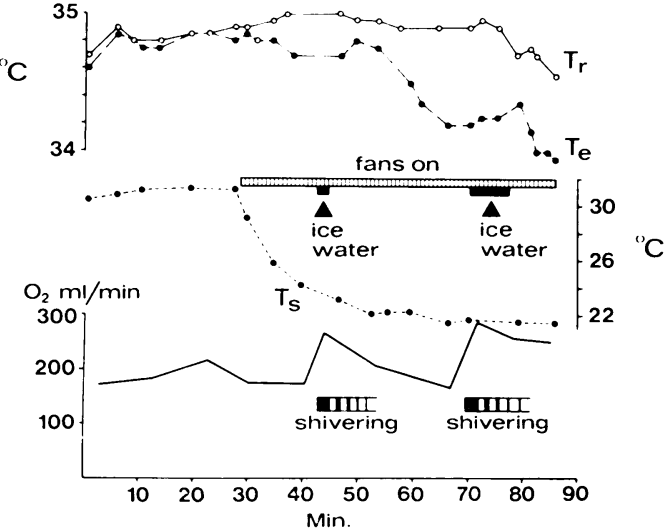

(b)

FIG. 2. Shivering and oxygen consumption in case 2 (S.B.). $\mathrm{T}_{\mathrm{r}}$ Rectal temperature. $\mathrm{T}_{\mathrm{e}}$ External auditory meatus temperature. $\mathrm{T}_{\mathrm{s}}$ Surface skin temperature on the trunk (one point). (a) During trunk cooling by fans (hatched bar): no shivering or rise of oxygen consumption in spite of considerable fall of central temperature. (b) During fan cooling with addition of immersion of feet in cold water (solid bars). 


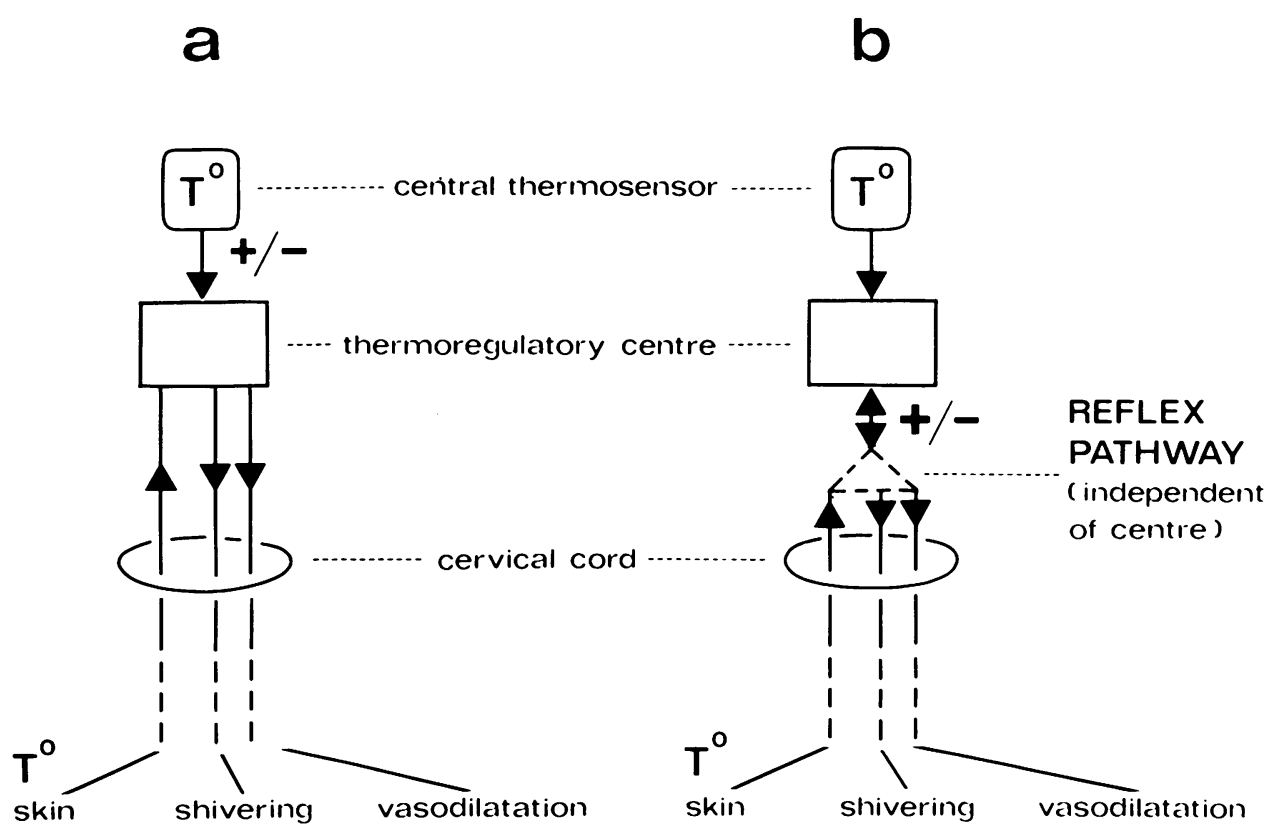

FIG. 3. Diagram of thermoregulatory reflexes in relation to central controlling mechanisms.

(a) Thermoregulatory reflexes dependent on integrity of the thermoregulatory centre, or (b) reflex pathways physiologically independent of the thermoregulatory centre but normally influenced by it.

(E.N.) the temperature measured in the external auditory meatus was initially $34.4^{\circ} \mathrm{C}$ and rose to $35^{\circ}$ C. Case 2 (S.B.) had an initial aural temperature of $33.6^{\circ} \mathrm{C}$ which rose to $34^{\circ} \mathrm{C}$, and case 3 (O.Y.) had an initial aural temperature of $35^{\circ} \mathrm{C}$ which rose to $35.7^{\circ} \mathrm{C}$. However, an increase of hand blood flow occurred at abnormally low temperatures in all three patients (Fig. 1).

Cooling, initially with fans and later by brief immersion of the feet in cold water, also produced abnormal responses (Table 2) although ventilation increased markedly. In case 1 (E.N.), although the central temperature fell from $35.3^{\circ} \mathrm{C}$ to $34.3^{\circ} \mathrm{C}$, neither method of cooling provoked visible shivering or piloerection, nor was there any change of oxygen consumption to indicate muscular activity not otherwise visible. In case 2 (S.B., Fig. 2a) and case 3 (O.Y.) fan cooling resulted in a fall of aural temperature from $34.8^{\circ} \mathrm{C}$ and $36^{\circ} \mathrm{C}$ to $33.9^{\circ} \mathrm{C}$ and $35.2^{\circ} \mathrm{C}$ respectively, without visible shivering or change in oxygen consump-
TABLE 2

RESULTS OF THERMOREGULATORY TESTS IN THREE PATIENTS

\begin{tabular}{lccc}
\hline & 1 & 2 & 3 \\
& $E . N$. & $S . B$. & $O . Y$. \\
$\begin{array}{l}\text { Shivering } \\
\text { with fall of central temperature } \\
\text { with immersion of feet in ice water }\end{array}$ & - & + & + \\
$\begin{array}{l}\text { Hand vasodilatation } \\
\text { in response to radiant heating of the } \\
\text { trunk } \\
\text { lowest central temperature at which } \\
\text { the vasodilatation occurred }\left({ }^{\circ} \mathrm{C}\right)\end{array}$ & $34 \cdot 4$ & $33 \cdot 6$ & 34 \\
\hline+ Present; - absent. & & &
\end{tabular}

tion. On subsequent occasions when the aural temperature was $34^{\circ} \mathrm{C}$ and $37^{\circ} \mathrm{C}$ respectively and in addition the feet were immersed in cold $\mathrm{D}$ water, obvious shivering occurred, together with a rise of oxygen consumption and a transient $N$ rise of central temperature. Shivering ceased 0 shortly after this additional cold stimulus to the N feet was removed (Fig. 2b). 


\section{DISCUSSION}

Our patients had evidence of a gross disorder of thermoregulation with no evidence of a disorder of the central or peripheral nervous system, or of autonomic nervous function. Circulatory reflexes were active since orthostatic hypotension was not present and other tests also indicated the integrity of efferent sympathetic pathways. The subjects also showed ventilatory stimulation on exposure to cold which did not depend upon a change in metabolism. This reflex is initiated by cold receptors in the skin, is mediated at midbrain level or below, and is independent of hypothalamic function (Keatinge and Nadel, 1965).

Evidence of defective thermoregulatory control was adduced from the presence of abnormal regulation of both vasodilatation and shivering. Vasodilatation may occur as a result of a rise in central temperature (Pickering, 1932) or reflexly from large areas of warmed skin (Kerslake and Cooper, 1950). In these patients reflex hand vasodilatation in response to radiant heating of the trunk occurred at abnormally low central temperatures. In case 1 (E.N.) it occurred after a slight rise of central temperature to $34.5^{\circ} \mathrm{C}$, while in the other two patients there was no delay, hand vasodilatation occurring when the central temperature was $33.5^{\circ} \mathrm{C}$ and $35.4^{\circ} \mathrm{C}$ respectively. Cooper et al. (1964) have shown that reflex hand vasodilatation as a result of radiant heating of the trunk normally occurs when the central temperature is above $36 \cdot 5^{\circ} \mathrm{C}$. This suggests that a central mechanism exerts an inhibitory influence on this reflex at lower temperatures. Cooper et al. also found that activation of the reflex was dependent upon the skin temperature of the warmed area, the reflex being progressively depressed as trunk skin temperature fell below $33^{\circ} \mathrm{C}$. The results we obtained in case 1 suggest that this mechanism may have been active, as hand vasodilatation commenced at an abnormally low central temperature only after the surface skin temperature of the trunk had reached at least $31-32^{\circ} \mathrm{C}$. It therefore appears that the afferent and efferent pathways for the reflex were functioning but that the central control of the reflex, which normally results in its inhibition at central temperatures below $36.5^{\circ} \mathrm{C}$, and prevents in- appropriate heat loss, was absent. These findings are similar to those obtained in other survivors of accidental hypothermia by Macmillan et al. (1967).

Shivering is normally provoked by a peripheral cold stimulus reinforced by a low central temperature, and usually produces a rise in central temperature (Johnson and Spalding, 1966; Bligh, 1966). Macmillan et al. (1967) demonstrated a failure of shivering in survivors of accidental hypothermia. In our three patients, cooling the trunk with fans produced a substantial fall of central temperature and also failed to elicit shivering. However, in two of these patients, chilling the feet did provoke shivering when the aural temperatures were $34^{\circ} \mathrm{C}$ and $37^{\circ} \mathrm{C}$ respectively. The absence of shivering when a large area of skin was cooled with fans indicated a failure of central receptors to respond to a considerable fall of central temperature and initiate shivering. Nevertheless, a more severe cold stimulus caused reflex shivering which occurred at a normal temperature $\left(37^{\circ} \mathrm{C}\right)$ in one patient and produced a rise in central temperature in both. The reflexes subserving shivering and vasodilatation pass above the level of the cervical spinal cord as a transverse lesion of the cord at this level abolishes them (Guttmann, Silver, and Wyndham, 1958; Appenzeller and Schnieden, 1963; Johnson and Spalding, 1964).

The central mechanisms for thermoregulation probably consist of two components, the first located in the posterior hypothalamus, controlling the 'set point' for body temperature, and a second, dependent on thermosensors, located in the anterior hypothalamus (Myers and Yaksh, 1971). Investigations upon animals indicate that the centre in the posterior hypothalamus is itself insensitive to change in temperature and it appears to act as an integrating centre or 'thermostat' for afferent impulses from the skin subserving cold sensation and impulses from the anterior hypothalamus (Hemingway, 1957; Benzinger, 1969). Our present observations in patients with disordered temperature regulation indicate that there are reflex pathways subserving shivering and vasodilatation independent of the central thermosensor and 'thermostat' (Fig. 3). Reflex shivering and vasodilatation 
may therefore occur independently of these central thermoregulatory mechanisms.

We wish to thank Professor G. M. Wilson and Dr. J. M. K. Spalding for referring patients, Professor J. A. Simpson for encouragement, and the Scottish Hospital Endowments Research Trust for financial support. D. M. P. was supported by the National Fund for Research into Crippling Diseases.

\section{REFERENCES}

Appenzeller, O., and Schnieden, H. (1963). Neurogenic pathways concerned in reflex vasodilatation in the hand with especial reference to stimuli affecting the afferent pathway. Clinical Science, 25, 413-421.

Bauer, H. G. (1954). Endocrine and other clinical manifestations of hypothalamic disease. A survey of 60 cases, with autopsies. Journal of Clinical Endocrinology, 14, 13-31.

Benzinger, T. H. (1969). Heat regulation: homeostasis of central temperature in man. Physiological Reviews, 49, 671759.

Bligh, J. (1966). The thermosensitivity of the hypothalamus and thermoregulation in mammals. Biological Reviews, 41, 317-367.

Cooper, K. E., Johnson, R. H., and Spalding, J. M. K. (1964). The effects of central body and trunk skin temperatures on reflex vasodilatation in the hand. Journal of Physiology, 174, 46-54.

Fox, R. H., Davies, T. W., Marsh, F. P., and Urich, H. (1970). Hypothermia in a young man with an anterior hypothalamic lesion. Lancet, 2, 185-188.

Gross, M. (1970). The effect of posture on subjects with cerebrovascular disease. Quarterly Journal of Medicine, 39, 485-491.
Guttmann, L., Silver, J., and Wyndham, C. H. (1958). Thermoregulation in spinal man. Journal of Physiology, 142, 406-419.

Hatfield, H. S. (1950). A heat-flow meter. Journal of Physiology, 111, 10-11P.

Hemingway, A. (1957). Nervous control of shivering. Alaskan Air Command Arctic Aeromedical Laboratory Technical Note AAL-TN-57-40. U.S. Arctic Aeromedical of Laboratory: Alaska.

Johnson, R. H., and Spalding, J. M. K. (1964). The effect of surface and central temperature on hand blood flow in subjects with complete transection of the cervical cord. Journal of Physiology, 171, 14-15P.

Johnson, R. H., and Spalding, J. M. K. (1966). The role of a $\overline{\overline{\bar{S}}}$ central temperature receptor in shivering in man. Journal 7 of Physiology, 184, 733-740.

Keatinge, W. R., and Nadel, J. A. (1965). Immediate respiratory response to sudden cooling of the skin. Journal of Applied Physiology, 20, 65-69.

Kerslake, D. McK., and Cooper, K. E. (1950). Vasodilatation in the hand in response to heating the skin elsewhere. $\infty$ Clinical Science, 9, 31-47.

Macmillan, A. L., Corbett, J. L., Johnson, R. H., Smith, A. C., Spalding, J. M. K., and Wollner, L. (1967). Temperature regulation in survivors of accidental hypothermia of the elderly, Lancet, 2, 165-169.

Myers, R. D., and Yaksh, T. L. (1971). Thermoregulation around a new 'set-point' established in the monkey by? altering the ratio of sodium to calcium ions within the hypothalamus. Journal of Physiology, 218, 609-633.

Pickering, G. W. (1932). The vasomotor regulation of hemit loss from the human skin in relation to external tempera ture. Heart, 16, 115-135.

Royal College of Physicians of London (1966). Report of the Committee on Accidental Hypothermia. RCP of Londono -

Sharpey-Schafer, E. P. (1955). Effect of Valsalva's manoeuvfe on the normal and failing circulation. British Medi@g Journal, 1, 693-695. 